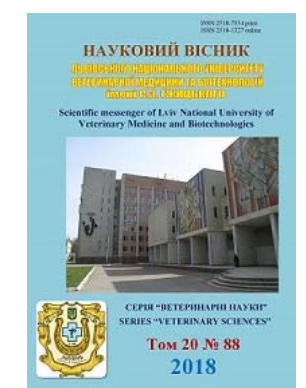

\author{
Науковий вісник Яьвівського національного університету \\ ветеринарної медицини та біотехнологій імені С.З. Гжицького
}

\author{
Scientific Messenger of Lviv National University \\ of Veterinary Medicine and Biotechnologies
}

ISSN 2518-7554 print

doi: $10.32718 /$ nvlvet8814

ISSN 2518-1327 online

UDC 619:636.7:612.141:616-71

\title{
Indirect evaluation method and parameters of blood pressure and its indexes in dogs
}

O.A. Dubova, A.A. Dubovyi, D.V. Feshchenko

Zhytomyr National Agroecological Univercity, Zhytomyr, Ukraine

Article info

Received 20.08.2018

Received in revised form 13.09.2018

Accepted 14.09.2018

Zhytomyr National Agroecological Univercity, Korolyova str., 39, Zhytomir, 10025, Ukraine. Tel.: +38-098-788-55-95 E-mail: oxdubova@gmail.com
Dubova, O.A., Dubovyi, A.A., \& Feshchenko, D.V. (2018). Indirect evaluation method and parameters of blood pressure and its indexes in dogs. Scientific Messenger of Lviv National University of Veterinary Medicine and Biotechnologies, 20(88), 80-84. doi: 10.32718/nvlvet8814

The article presents the results of studies on the adaptation of the automatic tonometer Longevita BP1305 with replaceable marking cuffs $I(C 1 I)$ and $C(C 1 C)$ for the oscillometric method of blood pressure measuring in dogs of different sizes. Reference indicators are defined. The proposed method is indirect and is based on the measurement of air pressure required to compress the artery and stop the blood flow in it. The initial recorded tone displays the maximum, or systolic, pressure (Sys). The process of stopping the registration of pulse tremors occurs at the time of restoration of the artery lumen and corresponds to the minimal, or diastolic, blood pressure (Dia). The use of the oscillometric method completely eliminates the human factor for the measurements. These cuffs allow to cover the whole range of the dogs circles subulnar zone of different breeds. The ratio of width to circumference is $42-45 \%$, which is the optimal value. The cuff of the device was applied to the left forearm area. Measurements were carried out three times, calculating the arithmetic mean of the results to account for the error caused by the stress state of animals. Experienced dogs were in the usual lying position. All healthy animals were monitored for blood pressure in the morning (9-10 hours), afternoon (14-15 hours) and evening (19-20 hours). Under the influence of aggressive factors of excessive force, inadequate violent chaotic reactions of the body occur, which leads to a state of shock. Periodic measurement of mean blood pressure in combination with other routine studies can identify patients at risk of decompensation at the stage when resuscitation is still possible. Systolic, diastolic blood pressure and pulse rate were measured. The mean blood pressure and Allgover shock index were calculated. We did not find a significant difference in blood pressure depending on body weight. Also, these figures fluctuate unreliably during the day and are the largest in the morning with a tendency to decrease in the evening. We have established the reference values of blood pressure of clinically healthy dogs at the level of the narrowed norm $(M \pm \sigma)$, taking into account the permitted number of the studied animals $(n=120)$. The shock index of Allgover in healthy animals is in the range of 0.6-0.9. The growth of the indicator indicates an increase in shock phenomena.

Key words: dogs, mean blood pressure, systolic blood pressure, diastolic blood pressure, pulse, shock state, shock index of Allgover, narrowed norm, reference indicators.

\section{Непрямий метод оцінки та показники артеріального тиску, його індексів у собак}

\author{
О.А. Дубова, А.А. Дубовий, Д.В. Фещенко
}

Житомирський національний агроекологічний університет, м. Житомир, Украӥна

У статті наведені результати досліджень з адаптачії автоматичного тонометра Longevita BP-1305 зі змінними манжетами маркування I(C1I) та С(С1C) для осиилометричного методу вимірювання артеріального тиску у собак різних розмірів. Визначено референтні показники. Запропонований спосіб є непрямим і трунтується на вимірі тиску повітря, що необхідне для стискання артерії і припинення в ній току крові. Початковий зареєстрований тон відображає максимальний, або систолічний, тиск (Sуs). Припинення реєстрачії пульсових поштовхів виникає в момент відновлення просвіту артерії і відповідає мінімальному, або діастолічному, тиску крові (Dia). Застосування осиилометричного методу повністю виключає людський фактор за проведення вимірів. Ці манжети дозволяють охопити увесь спектр окружностей підліктьової зони собак різних порід. Відношення ширини до окружності становить 42-45\%, що є оптимальною величиною. Манжету приладу накладали на підліктьову зону лівого передпліч- 
чя. Вимірювання проводили тричі, вираховуючи середньоарифметичне значення отриманих результатів для урахування похибки, спричиненої стресовим станом тварини. Дослідні собаки перебували в звичайному лежачому положенні. Усім здоровим тваринам проводили моніторинг артеріального тиску вранці (9-10 година), вдень (14-15 година) та ввечері (19-20 година). За умов впливу агресійних факторів надмірної сили відбуваються неадекватні бурхливі хаотичні реакиї організму, щзо призводить до шокового стану. Періодичне вимірювання середнього артеріального тиску в поєднанні з іншими рутинними дослідженнями дозволяє виявити пацієнтів з ризиком розвитку декомпенсації на тій стадії, коли реанімація ще можлива. Вимірювали систолічний, діастолічний артеріальний тиск та частоту пульсу. Вираховували середній артеріальний тиск та шоковий індекс Альговера. Ми не виявили достовірної різниці у показниках артеріального тиску залежно від маси тіла. Також иі показники недостовірно коливаються протягом доби і є найбільшими зранку з тенденцією до зниження надвечір. Нами було встановлено референтні показники артеріального тиску клінічно здорових собак на рівні звуженого нормативу $(M \pm \sigma)$, враховуючи дозволену для иьього кількість досліджених тварин $(n=120)$. Шоковий індекс Альговера у здорових тварин перебуває у межах 0,6-0,9. Зростання показника свідчить про наростання шокових явищ.

Ключові слова: собаки, середній артеріальний тиск, систолічний артеріальний тиск, діастолічний артеріальний тиск, пульс, шоковий стан, шоковий індекс Альговера, звужений норматив, референтні показники.

\section{Вступ}

Кров - внутрішнє середовище організму, утворене рідкою сполучною тканиною. Притаманні функції вона може здійснювати лише за умови ії постійного руху кровоносними судинами. Судини в канальцевій системі, серце як насос та власне кров - ланки апарату регулювання, який має назву гемодинамостат (Zajchik and Churilov, 2005).

Актуальність теми. Відповідно до законів гідродинаміки рух крові судинами визначається двома силами: різницею тиску на початку та у кінці судини і гідравлічним опором, що перешкоджає току крові. Відношення різниці тиску до опору визначає об'ємну швидкість току рідини, що тече судинами за одиницю часу. Ця залежність отримала назву основного гідродинамічного закону.

Кров'яний (артеріальний) тиск - це тиск крові на стінки кровоносних (артеріальних) судин організму. Величина його залежить від трьох основних факторів: частоти і сили серцевих скорочень, величини периферичного опору, тобто тонусу стінок судин, та об'єму циркулюючої крові (Lee et al., 2005; Zajchik and Churilov, 2005).

Показники артеріального тиску та його індексів змінюються за умови впливу на організм тварини агресивних факторів. Відомо (Blann et al., 2003; Zajchik and Churilov, 2005; Carcillo et al., 2007; Oliveira et al., 2008), що такі фактори спричиняють неадекватні бурхливі хаотичні реакції організму, що приводить до шокового стану - патологічного процесу, що супроводжується прогресивним порушенням життєво важливих функцій. За таких умов біологічно активні речовини, що $є$ домінуючими за розвитку шоку, ведуть до перерозподілу і централізації кровообігу, навіть зі збитками для багатьох органів. Важкість шокового стану оцінюється індексом Альговера (“шоковим індексом”) (Inwald et al., 2009; Rhodes et al., 2017).

Отже, вимірювання та оцінка артеріального тиску та його індексів мають надзвичайне значення у клінічній практиці лікаря ветеринарної медицини для оцінки загального стану тварини і встановлення необхідності проведення заходів невідкладної терапії (Vingfild, 2000).

Мета роботи - визначення фізіологічних значень артеріального тиску собак та індексів гемодинаміки, адаптація електронного автоматичного тонометру для проведення досліджень.

\section{Матеріал і методи досліджень}

Матеріалом досліджень стали 120 собак віком 28 років різних порід і статі. Було сформовано 2 групи тварин: I - собаки з масою 10-20 кг, $\mathrm{n}=70, \mathrm{II}-30-50$ кг, $\mathrm{n}=50$.

Артеріальний тиск визначали неінвазійним осцилометричним методом з використанням автоматичного тонометра Longevita BP-1305, що має живлення від електромережі для виключення похибок, пов'язаних зі слабкістю акумуляторів. Застосовували манжети маркування: I (C1I) - окружність передпліччя 1119 см, ширина 8 см, та С (C1C) - окружність передпліччя 17-24 см, ширина 11 см. Ці манжети дозволяють охопити увесь спектр окружностей підліктьової зони собак різних порід. Відношення ширини до окружності становить 42-45\%, що є оптимальною величиною (Vingfild, 2000; Saka et al., 2005; Kato et al., 2010).

Манжету приладу накладали на підліктьову зону лівого передпліччя. Вимірювання проводили тричі, вираховуючи середньоарифметичне значення отриманих результатів для урахування похибки, спричиненої стресовим станом тварини. Дослідні собаки перебували в звичайному лежачому положенні.

Усім здоровим тваринам проводили моніторинг артеріального тиску вранці (9-10 годин), вдень (14-15 годин) та ввечері (19-20 годин). Час виміру вибирали умовно (Vingfild, 2000; Korneva and Kuznetsova, 2016).

Визначали систолічний (Sys), діастолічний (Dia) тиск, частоту пульсу (P). Розраховували середній артеріальний тиск за формулою (Vingfild, 2000):

Середній $\mathrm{AT}=($ Sys - Dia $) / 3+$ Dia.

Шоковий індекс Альговера (Cai and Harrison, 2000; Hermann and Lerman, 2001; Oliveira et al., 2008; Brierley et al., 2009) визначали формулою:

Індекс Альговера = P / Sys.

Статистичну обробку отриманих результатів проводили 3 використанням пакета прикладних програм Statistica 13.3. Достовірність результатів оцінювали за t-критерієм Ст'юдента на 5\% довірчому рівні.

\section{Результати та їх обговорення}

Величина кров'яного тиску відображає багато параметрів гемодинамічної складової життєдіяльності організму (Hermann and Lerman, 2001; Blann et al., 2003; Zajchik and Churilov, 2005; Kato et al., 2010; 
Korneva and Kuznetsova, 2016). Прийнято вимірювати максимальний та мінімальний тиск. Досить інформативним і застосованим у клінічній практиці є непрямий метод виміру, що грунтується на вимірі тиску повітря, яке необхідне для стискання артерії і припинення в ній току крові. Початковий тон, який прослуховується після стискання артерії, виникає під час проходження крові поштовхами через стиснену артерію та відображає максимальний, або систолічний тиск. Припинення звукових явищ виникає в момент відновлення просвіту артерій і відповідає мінімальному, або діастолічному, тиску крові (Vingfild, 2000; Hermann and Lerman, 2001; Korneva and Kuznetsova, 2016).

Оскільки аускультативний метод вимірювання тиску значно залежить від людського фактора, останнім часом надають перевагу вимірюванням осцилометричним методом (Vingfild, 2000). За такого способу артеріальний тиск вимірюється електронним тонометром. Прилад реєструє пульсації в манжеті, які 3'являються, коли кров проходить через стиснуту ділянку судини. Таким чином, індивідуальні якості спеціаліста, який проводить вимірювання, а саме: зір, слух, рухи - значення не мають. Також прилад здатний визначати артеріальний тиск за слабких тонів Короткова (Vingfild, 2000).

Визначення середнього артеріального тиску як один $з$ елементів клінічного огляду має надзвичайне діагностичне значення. Непрямого моніторингу кров'яного тиску потребують тварини з нестабільним або потенційно нестабільним серцево-судинним статусом (травматичні пошкодження, панкреатит, захворювання нирок, розширення шлунка, заворот кишок, гіпотіреоз тощо). Непрямий метод вимірювання кров'яного тиску показаний пацієнтам за виконання їм загальної анестезії.

У тварин, що перебувають в критичних станах, середній артеріальний тиск підтримується в нормальних межах компенсаторними механізмами до моменту виникнення важких порушень. Періодичне вимірювання середнього артеріального тиску в поєднанні 3 іншими рутинними дослідженнями дозволяє виявити пацієнтів з ризиком розвитку декомпенсації на тій стадіï, коли реанімація ще можлива (Vingfild, 2000; Oliveira et al., 2008).

Ми провели адаптацію автоматичного тонометра Longevita BР-1305 для вимірювання артеріального тиску у собак. Загальновідомою є думка про похибки вимірювання i коливання показників залежно від зовнішніх факторів, як то: час доби, стрес, присутність або відсутність власника/доглядача тощо.

За проведення власних досліджень ми намагалися створити оптимальні умови, мінімізувати фактор стресу. Для вирівнювання даних виміри проводили тричі поспіль. Умови досліджень були однаковими.

Результати значень артеріального тиску та його індексів у тварин з різною масою тіла наведені у таблиці 1.

\section{Таблиця 1}

Показники артеріального тиску та його індексів у клінічно здорових собак залежно від маси тіла (M \pm m)

\begin{tabular}{lcc}
\hline \multicolumn{1}{c}{ Показник } & Собаки масою $10-20$ кг, $\mathrm{n}=70$ & Собаки масою $30-50$ кг, $\mathrm{n}=50$ \\
\hline Sуs, мм рт. ст. & $135,6 \pm 4,7$ & $122,4 \pm 2,6$ \\
Dia, мм рт. ст. & $85,5 \pm 4,1$ & $85,9 \pm 5,7$ \\
Пульс, уд./хв & $100,2 \pm 3,4$ & $96 \pm 5,6$ \\
Середній артеріальний тиск, мм рт. ст. & $105,8 \pm 3,8$ & $97,4 \pm 4,5$ \\
Шоковий індекс (індекс Альговера) & $0,76 \pm 0,17$ & $0,79 \pm 0,2$ \\
\hline
\end{tabular}

Як видно з наведених результатів (табл. 1), достовірної різниці в показниках артеріального тиску та його індексів залежно від маси тіла не встановлено.
Незважаючи на те, що величина артеріального тиску є одним з досить сталих елементів гомеостазу, все ж виявляються певні коливання залежно від часу доби. Результати вимірів наведені в таблиці 2.

\section{Таблиця 2}

Коливання показників артеріального тиску собак залежно від часу доби, $\mathrm{n}=30$

\begin{tabular}{lrrr}
\hline \multicolumn{1}{c}{ Показник } & ранок & \multicolumn{1}{c}{ день } & вечір \\
\hline Sуs, мм рт. ст. & $130,6 \pm 3,8$ & $119,8 \pm 4,4$ & $122,3 \pm 4,0$ \\
Diа, мм рт. ст. & $87,3 \pm 3,2$ & $86,1 \pm 2,2$ & $84,3 \pm 3,2$ \\
Пульс, уд./хв & $106,3 \pm 5,4$ & $95,2 \pm 3,1$ & $91,2 \pm 3,5$ \\
Середній АТ, мм рт.ст. & $102,5 \pm 5,7$ & $98,8 \pm 4,8$ & $98,2 \pm 3,3$ \\
Індекс Альговера & $0,8 \pm 0,07$ & $0,79 \pm 0,1$ & $0,76 \pm 0,13$ \\
\hline
\end{tabular}

Аналізуючи отримані дані, потрібно відмітити, що коливання показників артеріального тиску та індексу Альговера відрізняються недостовірно впродовж доби, хоча $є$ найбільшими зранку і мають тендецію до зниження до вечірніх годин.
Враховуючи той факт, що достовірної різниці у показниках артеріального тиску залежно від маси тіла та часу доби не встановлено, ми визначили контрольні показники артеріального тиску клінічно здорових собак, $\mathrm{M} \pm \mathrm{m}, \mathrm{n}=120$ (табл. 3), на рівні звуженого нормативу $(\mathrm{M} \pm \sigma)$. 
Таблиця 3

Звужені нормативні показники артеріального тиску клінічно здорових собак, $\mathrm{n}=120$

\begin{tabular}{lccc}
\hline \multicolumn{1}{c}{ Показник } & $\mathrm{M} \pm \mathrm{m}$ & $\sigma$ & Звужений норматив * \\
\hline Sуs, мм рт. ст. & $126,8 \pm 1,8$ & 19,8 & $105-145$ \\
Dia, мм рт. ст. & $88,5 \pm 1,3$ & 14,3 & $75-100$ \\
Середній АТ, мм рт.ст. & $102,1 \pm 1,8$ & 19,8 & $80-120$ \\
Пульс, уд./хв & $101,6 \pm 1,6$ & 17,6 & $85-120$ \\
Індекс Альговера & $0,79 \pm 0,01$ & 0,11 & $0,7-0,9$ \\
\hline
\end{tabular}

Примітка: *-результати заокруглені для зручності використання

Середній артеріальний тиск $є$ величиною розрахунковою. Вона визначає перфузійний тиск для основних органів. Для підтримки мінімального кровотоку у нирках, мозку та печінці середній АТ повинен становити 60 мм рт. ст., а для адекватної коронарної перфузії потрібний мінімальний діастолічний тиск 40 мм рт. Ст (Vingfild, 2000).

У зв'язку з тим, що рівень артеріального тиску не завжди відповідає важкості стану хворої тварини і не завжди відображає ступінь крововтрати, оскільки може бути централізація кровообігу, необхідно оцінити величину крововтрати залежно від характеру пошкодження і гемодинамічних показників.

Визначення об'єму крововтрати засноване на відношенні частоти пульсу до рівня систолічного артеріального тиску (індекс Альговера, або шоковий індекс). У клінічно здорових тварин він становить 0,60,9. Зростання індексу Альговера свідчить про наростання шокових явищ (Carcillo et al., 2007; Inwald et al., 2009; Rhodes et al., 2017).

Узагальнюючи результати проведених досліджень, ми можемо зазначити, що непрямий метод оцінки артеріального тиску визначає деякі змінні величини, що належать до кровотоку. Величину кров'яного тиску, грунтуючись на даних непрямого методу виміру, розраховують так (Vingfild, 2000):

$$
\begin{gathered}
\text { Артеріальний тиск = сериевий викид * розтягне- } \\
\text { ність судин * об'єм крові }
\end{gathered}
$$

Осцилометричний метод $є$ досить точним, хоча вимагає повторних вимірювань для вирівнювання та точності показників з поправкою на стрес-фактори у тварини.

Визначені нами показники нормального артеріального тиску та його індексів у собак відображають стан систем гемодинаміки організму, що є однією 3 важливих складових гомеостазу.

Використання автоматичного електронного тонометра Longevita ВР-1305 зі змінними манжетами залежно від окружності підліктьової зони адекватно і точно відображає значення показників артеріального тиску в собак і може бути рекомендований до використання в клініці як зручний, недорогий, безболісний i нетравматичний метод. Тонометр може бути використаний за будь-яких умов, що збільшує практичну цінність методу.

\section{Висновки}

1. Для непрямого дослідження артеріального тиску в собак адаптований осцилометричний метод 3 використанням автоматичного електронного тономе- тра Longevita BP-1305 зі змінними манжетами класу $\mathrm{I}(\mathrm{C} 1 \mathrm{I})$ та $\mathrm{C}(\mathrm{C} 1 \mathrm{C})$, що дозволяє охопити увесь спектр окружностей підліктьової зони у собак.

2. Дослідження проводяться за накладання манжети на підліктьову зону лівого передпліччя у трьох повторах з підрахунком середніх результатів.

3. Показники артеріального тиску не мають достовірних відмінностей залежно від маси тварини або часу доби.

4. Клінічно значущими є визначення середнього артеріального тиску та індексу Альговера, що визначають гемодинамічний статус організму собаки.

Перспективи подальших досліджень полягають у встановленні гемодинамічного статусу собак за різних важких патологій і виявленні шокових осей ускладнень шляхом використання показників артеріального тиску та його індексів. Своєчасний моніторинг цих параметрів дозволить виявити та оцінити ступінь важкості ускладнення і застосувати заходи невідкладної терапії хворої тварини, чим запобігти загибелі.

\section{References}

Blann, A.D., Nadar, S., \& Lip, G.Y. (2003). Pharmacological modulation of platelet function in hypertension. Hypertension, 42(1), 1-7. doi: 10.1161/01.HYP.0000077901.84467.E1.

Brierley, J., Carcillo, J.A., Choong K. et al. (2009). Clinical practice parameters for hemodynamic support of pediatric and neonatal septic shock: 2007 update from the American College of Critical Care Medicine. Crit. Care Med., 37(2), 666-688. doi: 10.1097/CCM.0b013e31819323c6.

Carcillo, J.A., Han, K., Lin, J., \& Orr, R. (2007). Goaldirected management of pediatric shock in the emergency department. Clinical Pediatric Emergency Medicine, 8(3), 165-175. doi: 10.1016/j.cpem.2007.07.002.

Hermann, J., \& Lerman, A. (2001). The endothelium: Dysfunction and beyong. J. Nuclear Cardiology, 8, 197-206. doi: 10.1067/mnc.2001.114148.

Cai, H., \& Harrison, D.G. (2000). Endothelial Dysfunction in Cardiovascular Diseases: The Role of Oxidant Stress. CircRes, 87, 840-844. doi: 10.1161/01.RES.87.10.840.

Inwald, D.P., Tasker, R.C., Peters, M.J., \& Nadel, S. (2009). Emergency management of children with severe sepsis in the United Kingdom: the results of the Paediatric Intensive Care Society sepsis audit. Arch. Dis. Child., 94(5), 348-53. doi: 10.1136/adc.2008.153064.

Kato, T., Niizuma, S., Inuzuka, Y. et al. (2010). Analysis of metabolic remodeling in compensated left ventricular 
hypertrophy and heart failure. Circ Heart Fail., 3(3), 420 30. doi: 10.1161/CIRCHEARTFAILURE.109.888479.

Lee, K.W., Blann, A.D., \& Lip, G.Y. (2005). High pulse pressure and nondipping circadian blood pressure in patients with coronary artery diseases: Relationship to thrombogenesis and endothelial damage / dysfunction. Am. J. Hypertens, 18(1), 104-115. doi: 10.1016/j.amjhyper.2004.09.003.

Oliveira, C.F., Nogueira de Sá, F.R., Oliveira, D.S. et al. (2008). Time- and fluid-sensitive resuscitation for hemodynamic support of children in septic shock: barriers to the implementation of the American College of Critical Care Medicine / Pediatric Advanced Life Support Guidelines in a pediatric intensive care unit in a developing world. Pediatr Emerg Care, 24(12), 810 815. doi: 10.1097/PEC.0b013e31818e9f3a.

Rhodes, A., Evans, L., Alhazzani, W., Levy, M. et al. (2017). Surviving Sepsis Campaign: International Guidelines for Managments of Sepsis and Septic
Shock. Critical Care Medicine, 45(3), 486-552. doi: 10.1097/CCM.0000000000002255.

Saka, B., Oflaz, H., Erten, N., Bahat, G. et al. (2005). Non-invasive evaluation of endothelial function in hypertensive eldery patients. Arch. Gerontol. Geriatr., 40(1), 61-71. doi: 10.1016/j.archger.2004.05.008.

Vingfild, V.E. (2000). Sekrety neotlozhnoj veterinarnoj pomoshhi. M. SPb.: "Izdatel'stvo BINOM" - "Nevskij dialekt", 567-575 (In Russian).

Zajchik, A.Sh., \& Churilov, L.P. (2005). Patofiziologija. Tom 3. Mehanizmy razvitija boleznej i sindromov. Kniga 1. Patofiziologicheskie osnovy gematologii i onkologii. JeLBI. SPb (In Russian).

Korneva, V.A., \& Kuznetsova, T.Yu. (2016). Otsenka pokazatelei zhestkosty arteryalnoi stenky pry sutochnom monytoryrovanyy arteryalnoho davlenyia. Terapevtycheskyi arkhyv, 9, 119-124 (in Russian). 